\title{
ATP-dependent chromatin remodeling and histone acetyltransferases in 5-FU cytotoxicity in Saccharomyces cerevisiae
}

R. Matuo ${ }^{1}$, F.G. Sousa ${ }^{1}$, D. Bonatto ${ }^{1}$, A.A. Mielniczki-Pereira' ${ }^{1,2}$, J. Saffi ${ }^{1,3}$, D.G. Soares ${ }^{4,5,6}$, A.E. Escargueil ${ }^{4,5,6}$, A.K. Larsen ${ }^{4,5,6}$ and J.A.P. Henriques ${ }^{1,7}$

${ }^{1}$ Centro de Biotecnologia, Departamento de Biofísica, Universidade Federal do Rio Grande do Sul, Porto Alegre, RS, Brasil ${ }^{2}$ Departamento de Ciências Biológicas, Universidade Integrada do Alto Uruguai e das Missões, Erechim, RS, Brasil ${ }^{3}$ Departamento de Ciências Básicas da Saúde, Bioquímica, Universidade Federal de Ciências da Saúde de Porto Alegre, Porto Alegre, RS, Brasil

${ }^{4}$ Laboratory of Cancer Biology and Therapeutics, Centre de Recherche Saint-Antoine, Paris, France

${ }^{5}$ Institut National de la Santé et de la Recherche Médicale, Paris, France

${ }^{6}$ Université Pierre et Marie Curie, Paris, France

${ }^{7}$ Instituto de Biotecnologia, Departamento de Ciências Biomédicas, Universidade de Caxias do Sul, Caxias do Sul, RS, Brasil

Corresponding author: J.A.P. Henriques

E-mail: pegas.henriques@gmail.com

Genet. Mol. Res. 12 (2): 1440-1456 (2013)

Received August 3, 2012

Accepted January 19, 2013

Published April 26, 2013

DOI http://dx.doi.org/10.4238/2013.April.26.6

ABSTRACT. Chromatin is thought to modulate access of repair
proteins to DNA lesions, and may be altered by chromatin remodelers
to facilitate repair. We investigated the participation of chromatin
remodelers and DNA repair in 5-fluorouracil (5-FU) cytotoxicity in
Saccharomyces cerevisiae. 5-FU is an antineoplastic drug commonly
used in clinical settings. Among the several strains tested, only those 
with deficiencies in ATP-dependent chromatin remodeling (CR) and some histone acetyltransferases (HAT) exhibited sensitivity to 5-FU. $\mathrm{CR}$ and HAT double-mutants exhibited increased resistance to 5-FU in comparison to the wild-type mutant, but were still arrested in G2/M, as were the sensitive strains. The participation of Htzlp in 5-FU toxicity was also evaluated in single- and double-mutants of CR and HAT; the most significant effect was on cell cycle distribution. 5-FU lesions are repaired by different DNA repair machineries, including homologous recombination (HR) and post-replication repair (PRR). We investigated the role of CR and HAT in these DNA repair pathways. Deficiencies in Nhp10 and CR combined with deficiencies in HR or PRR increased 5-FU sensitivity; however, combined deficiencies of HAT, HR, and PRR did not. CRs are directly recruited to DNA damage and lead to chromatin relaxation, which facilitates access of HR and PRR proteins to 5-FU lesions. Combined deficiencies in HAT with defects in HR and PRR did not potentiate 5-FU cytotoxicity, possibly because they function in a common pathway.

Key words: 5-FU; ATP-dependent chromatin remodelers; Histone acetyltransferases; Homologous recombination repair; Post-replication repair

\section{INTRODUCTION}

Most antineoplasic drugs target the DNA of cancer cells to create cytotoxic effects. This cytotoxicity may be related to DNA damage induction as single- (SSBs) and doublestrand breaks (DSBs), inter- and intra-strand crosslinks, and interference in purine and pyrimidine metabolism (Ding et al., 2006). Since the DNA damage may be repaired by different cellular DNA repair machineries, efficient repair of these lesions could result in drug resistance and chemotherapy failure (Wyatt and Wilson III, 2009). Therefore, therapies targeting DNA repair have emerged as promising approaches in anticancer research.

Efficient DNA repair depends on many factors, including how the DNA is packaged with histones and non-histone proteins into chromatin. Highly condensed structures likely do not allow access of the DNA-associated repair factors to the lesions (Ataian and Krebs, 2006; Escargueil et al., 2008; Huertas et al., 2009). The first step in chromatin packaging consists of $146 \mathrm{bp}$ of DNA wrapped around a histone octamer containing 2 copies each of the core histones $\mathrm{H} 2 \mathrm{~A}, \mathrm{H} 2 \mathrm{~B}, \mathrm{H} 3$, and H4. This structure may be modified by chromatin-modifying enzymes that act as i) covalent post-translational histone tail modifiers (acetylation, methylation, phosphorylation, and ubiquitylation) or ii) ATP-dependent remodelers (Altaf et al., 2007; Osley et al., 2007). Covalent modifications alter the charge of specific residues, affecting histone-histone and histone-DNA interactions, and signaling to other protein complexes. Chromatin remodeling depends on multi-protein complexes, which employ ATP hydrolysis energy to alter the histone-DNA interaction. These complexes act by sliding nucleosomes in the DNA molecule, restricting access to specific sequences (for review, see Gangaraju and Bartholomew, 2007; Escargueil et al., 2008) or inserting the histone variants into nucleosomes, which may alter the higher-order chromatin structure (Henikoff and Ahmad, 2005; Altaf et al., 2007). 
Our study was designed to investigate the involvement of DNA repair and chromatin structure modifiers in response to the antineoplasic drug 5-fluorouracil (5-FU). We employed Saccharomyces cerevisiae as a genetically tractable model organism with many features of chromatin and DNA repair that are common to human cells. 5-FU is an antimetabolite analog of uracil that must be converted to its active metabolites for cytotoxic effect (for review, see Wyatt and Wilson III, 2009). These metabolites could be misincorporated into DNA (Kufe et al., 1981) and RNA (Kufe and Major, 1981) or result in nucleotide pool imbalance (Noordhuis et al., 2004). Many aspects of the 5-FU action mechanism have already been reported (Noordhuis et al., 2004; Matuo et al., 2009); however, the involvement of DNA repair associated with chromatin remodelers for 5-FU cytotoxicity has not been described.

\section{MATERIAL AND METHODS}

\section{Yeast strains and growth conditions}

Yeast strains deficient in chromatin remodelers and post-translational chromatin modifiers were kindly provided by Dr. Lisiane Meira (Biological Engineering Division, MIT, Cambridge, USA), acquired from Euroscarf (European S. cerevisiae Archive for Functional Analysis), or constructed by gene replacement. Relevant genotypes of the $S$. cerevisiae strains used in this study are indicated in Table 1. For routine growth, complete liquid medium (YPD) containing $1 \%(\mathrm{w} / \mathrm{v})$ yeast extract, $2 \%(\mathrm{w} / \mathrm{v})$ bacto-peptone, and $2 \%(\mathrm{w} / \mathrm{v})$ glucose was employed. Medium containing $2 \%(\mathrm{w} / \mathrm{v})$ bacto-agar was used for plates. Synthetic medium containing $1.7 \mathrm{~g} / \mathrm{L}$ yeast nitrogen base, $5 \mathrm{~g} / \mathrm{L}$ ammonium sulfate, $20 \mathrm{~g} / \mathrm{L}$ glucose, supplemented with the appropriate amino acids $(40 \mathrm{~g} / \mathrm{mL})$ was employed for selection of transformants.

Experiments were performed in exponential phase (Log). Log cultures were obtained by inoculation of $5 \times 10^{6}$ cells $/ \mathrm{mL}$ YPD overnight cultures into $5 \mathrm{~mL}$ fresh YPD medium. After 3 -h incubation at $30^{\circ} \mathrm{C}$ with aeration, the cultures contained 1 to $2 \times 10^{7}$ cells $/ \mathrm{mL}$. The number of cells was determined by counting in a Neubauer chamber.

\section{5-FU sensitivity assays}

In order to pre-determine 5-FU sensitivity and optimal drug range, logarithmic cultures were serially diluted by $1: 10$ between $10^{7}$ to $10^{3}$ cells $/ \mathrm{mL}$ and $4-\mu \mathrm{L}$ aliquots were spotted onto rich medium plates with or without 5-FU. Plates were incubated at $30^{\circ} \mathrm{C}$ for 2 days. Experiments were performed at least twice for each dose and on independent days.

\section{Cytotoxicity and cytostatic effect evaluation by poissoner quantitative drop test (PQDT)}

The PQDT protocol was described by Poletto et al. (2009) and was employed with minor modifications. Cytotoxicity was measured by survival assays after 5-FU treatments on YPD plates and cytostatic activity was evaluated by colony area measurement estimated from scanned images of Petri plates, using the ImageJ Analysis Software (version 1.39; National Institutes of Health, Bethesda, MD, USA, http://rsb.info.nih.gov/ij/). Graphics represent the average of three independent experiments. 


\begin{tabular}{|c|c|c|c|}
\hline Strains & Relevant genotypes & Pathway affected & Source \\
\hline BY4741 (WT) & MATa; his $3 \Delta 1 ;$ leu $2 \Delta 0 ;$ met $15 \Delta 0 ;$ ura $3 \Delta 0$ & - & Euroscarf \\
\hline hhols & BY4741; with hho1::kanMX4 & H1 histone & Euroscarf \\
\hline htals & BY4741; with hta1::kanMX4 & $\mathrm{H} 2 \mathrm{~A}$ histone & Euroscarf \\
\hline$h t b 2 \Delta$ & BY4741; with htb2::kanMX4 & $\mathrm{H} 2 \mathrm{~B}$ histone & Euroscarf \\
\hline hht $1 \Delta$ & BY4741; with hht $1:$ kanMX4 & $\mathrm{H} 3$ histone & Euroscarf \\
\hline$h h f 1 \Delta$ & BY4741; with hhfl::kanMX4 & H4 histone & Euroscarf \\
\hline nhp10八 & BY4741; with nhp $10:$ kanMX4 & HMG & L. Meira \\
\hline $\operatorname{arp} 4 \Delta$ & BY4741; with $\operatorname{arp} 4: \because k a n M X 4$ & $\mathrm{CR}$ & L. Meira \\
\hline ino80A & BY4741; with ino $80: \because k a n M X 4$ & $\mathrm{CR}$ & L. Meira \\
\hline swrls & BY4741; with swrl::kanMX4 & $\mathrm{CR}$ & L. Meira \\
\hline elp $3 \Delta$ & BY4741; with elp $3::$ kanMX4 & HAT & L. Meira \\
\hline esals & BY4741; with esa $1:$ kanMX4 & HAT & L. Meira \\
\hline $\operatorname{gcn} 5 \Delta$ & BY4741; with gcn $5:$ kanMX4 & HAT & L. Meira \\
\hline hat1s & BY4741; with hat $1:$ kanMX4 & HAT & L. Meira \\
\hline hat $2 \Delta$ & BY4741; with hat $2:: k a n M X 4$ & HAT & L. Meira \\
\hline hpa $2 \Delta$ & BY4741; with hpa $::$ kanMX4 & HAT & L. Meira \\
\hline hpa3s & BY4741; with hpa $3:$ kanMX4 & HAT & L. Meira \\
\hline $\operatorname{sas} 2 \Delta$ & BY4741; with sas $2: \because k a n M X 4$ & HAT & L. Meira \\
\hline $\operatorname{sas} 3 \Delta$ & BY4741; with sas $3:: k a n M X 4$ & HAT & L. Meira \\
\hline$u b c 4 \Delta$ & BY4741; with $u b c 4: \because k a n M X 4$ & UB & Euroscarf \\
\hline$u b c 5 \Delta$ & BY4741; with $u b c 5:: k a n M X 4$ & UB & Euroscarf \\
\hline hdals & BY4741; with hda1::kanMX4 & HDAC & L. Meira \\
\hline $\sin 3 \Delta$ & BY4741; with $\sin 3:: \operatorname{kanMX} 4$ & HDAC & L. Meira \\
\hline $\operatorname{sir} 2 \Delta$ & BY4741; with sir $2:$ kanMX4 & HDAC & L. Meira \\
\hline hos $1 \Delta$ & BY4741; with hos $1:$ kanMX4 & HDAC & L. Meira \\
\hline $\operatorname{hos} 2 \Delta$ & BY4741; with hos $2:$ kanMX4 & HDAC & L. Meira \\
\hline $\operatorname{hos} 3 \Delta$ & BY4741; with hos $3:$ kanMX4 & HDAC & L. Meira \\
\hline hst $1 \Delta$ & BY4741; with hst $1 \because$ kanMX4 & HDAC & L. Meira \\
\hline hst $2 \Delta$ & BY4741; with hst $2:$ kanMX4 & HDAC & L. Meira \\
\hline hst $3 \Delta$ & BY4741; with hst $3: \because k a n M X 4$ & HDAC & L. Meira \\
\hline hst $4 \Delta$ & BY4741; with hst4::kanMX4 & HDAC & L. Meira \\
\hline$r p d 3 \Delta$ & BY4741; with rpd3::kanMX4 & HDAC & L. Meira \\
\hline $\operatorname{dot} 1 \Delta$ & BY4741; with dot $1:: \operatorname{kan} M X 4$ & HML & L. Meira \\
\hline msils & BY4741; with msil::kanMX4 & HMT & Euroscarf \\
\hline $\operatorname{set} 2 \Delta$ & BY4741, with set $2:: k a n M X 4$ & HMT & Euroscarf \\
\hline $\operatorname{rph} 1 \Delta$ & BY4741; with $\operatorname{rph} 1:: k a n M X 4$ & HDML & Euroscarf \\
\hline$h t z 1 \Delta$ & BY4741; with htzl::LEU2 & $\mathrm{HV}$ & This study \\
\hline $\operatorname{arp} 4 \Delta h t z 1 \Delta$ & BY4741; with arp $4: \because k a n M X 4$, tz $1: \because L E U 2$ & $\mathrm{CR} / \mathrm{HV}$ & This study \\
\hline hat $1 \Delta \operatorname{arp} 4 \Delta$ & BY4741; with hat $1:: \operatorname{kanM} X 4$, arp $4:: U R A 3$ & $\mathrm{HAT} / \mathrm{CR}$ & This study \\
\hline hat $1 \Delta$ esals & BY4741; with hat $1:$ kanMX4, esa1::URA3 & HAT & This study \\
\hline hat $1 \Delta h t z 1 \Delta$ & BY4741; with hat $1:$ kanMX4, htz1::LEU2 & $\mathrm{HAT} / \mathrm{HV}$ & This study \\
\hline esal $\Delta h t z 1 \Delta$ & BY4741; with esa1::kanMX4, htz1::LEU2 & $\mathrm{HAT} / \mathrm{HV}$ & This study \\
\hline $\operatorname{rad} 6 \Delta$ & BY4741; with rad6::LEU2 & PRR & This study \\
\hline $\operatorname{rad} 52 \Delta$ & BY4741; with $\operatorname{rad} 52: \because L E U 2$ & HR & This study \\
\hline$x r s \Delta$ & BY4741; with $x r s 2:: L E U 2$ & HR & This study \\
\hline nhp $10 \Delta \mathrm{rad} 6 \Delta$ & BY4741; with nhp $10: \because k a n M X 4, \operatorname{rad} 6: \because L E U 2$ & HMG/PRR & This study \\
\hline nhp $10 \Delta \operatorname{rad} 52 \Delta$ & BY4741; with $\operatorname{nhp} 10: \because \operatorname{kan} M X 4, \operatorname{rad} 52: \because L E U 2$ & $\mathrm{HMG} / \mathrm{HR}$ & This study \\
\hline$n h p 10 \Delta x r s 2 \Delta$ & BY4741; with nhp $10: \because$ kanMX $4, x r s 2:: L E U 2$ & $\mathrm{HMG} / \mathrm{HR}$ & This study \\
\hline hat $1 \Delta$ rad $6 \Delta$ & BY4741; with hat $1:$ kan $M X 4$, rad6::LEU2 & $\mathrm{HAT} / \mathrm{PRR}$ & This study \\
\hline hat $1 \Delta \operatorname{rad} 52 \Delta$ & BY4741; with hat $1: \operatorname{kanMX} 4, \operatorname{rad} 52: \because$ LEU2 & $\mathrm{HAT} / \mathrm{HR}$ & This study \\
\hline hat $1 \Delta x r s 2 \Delta$ & BY4741; with hat1 ::kanMX4, xrs $2:: L E U 2$ & $\mathrm{HAT} / \mathrm{HR}$ & This study \\
\hline $\operatorname{gcn} 5 \Delta \operatorname{rad} 6 \Delta$ & BY4741; with $\operatorname{gcn} 5: \because \operatorname{kan} M X 4, \operatorname{rad} 6:: L E U 2$ & $\mathrm{HAT} / \mathrm{PRR}$ & This study \\
\hline $\operatorname{gcn} 5 \Delta \operatorname{rad} 52 \Delta$ & BY4741; with gcn $5: \because k a n M X 4, \operatorname{rad} 52: \because L E U 2$ & $\mathrm{HAT} / \mathrm{HR}$ & This study \\
\hline$g c n 5 \Delta x r s 2 \Delta$ & BY4741; with gcn $5: \because k a n M X 4, x r s 2: \because L E U 2$ & $\mathrm{HAT} / \mathrm{HR}$ & This study \\
\hline ino $80 \Delta \mathrm{rad} 6 \Delta$ & BY4741; with ino $80::$ kanMX4, rad6 $:$ LEU2 & $\mathrm{CR} / \mathrm{PRR}$ & This study \\
\hline ino $80 \Delta \operatorname{rad} 52 \Delta$ & BY4741; with ino $80: \because k a n M X 4, \operatorname{rad} 52:: L E U 2$ & $\mathrm{CR} / \mathrm{HR}$ & This study \\
\hline ino $80 \Delta x r s 2 \Delta$ & BY4741; with ino $80:: k a n M X 4, x r s 2:: L E U 2$ & $\mathrm{CR} / \mathrm{HR}$ & This study \\
\hline swr $1 \Delta \operatorname{rad} 6 \Delta$ & BY4741; with swrl ::kanMX4, rad6::LEU2 & $\mathrm{CR} / \mathrm{PRR}$ & This study \\
\hline swr $1 \Delta \operatorname{rad} 52 \Delta$ & BY4741; with swr $1: \because k a n M X 4, \operatorname{rad} 52: \because L E U 2$ & $\mathrm{CR} / \mathrm{HR}$ & This study \\
\hline$s w r 1 \Delta x r s 2 \Delta$ & BY4741; with swr $1: \because \operatorname{kan} M X 4, x r s 2: \because L E U 2$ & $\mathrm{CR} / \mathrm{HR}$ & This study \\
\hline
\end{tabular}

$\mathrm{HMG}=$ high-mobility group non-histone protein; $\mathrm{CR}=$ ATP-dependent chromatin remodeling; HAT $=$ histone acetyltransferase; $\mathrm{UB}=$ ubiquitin; $\mathrm{HDAC}=$ histone deacetylase; $\mathrm{HML}=$ histone methylase; $\mathrm{HMT}=$ histone methyltransferase; $\mathrm{HDML}=$ histone demethylase; $\mathrm{HV}=$ histone variant; $\mathrm{PRR}=$ post-replication repair; $\mathrm{HR}=$ homologous recombination. 


\section{Construction of double-mutants}

Double-mutants were obtained by disruption of ARP4, ESA1, HTZ1, RAD6, RAD52, and XRS2 by homologous recombination. The bifunctional yeast/Escherichia coli vector YcpLac33 was used as template for amplification of arp 4::URA3 and esa1::URA3 disruption cassettes. pGadT7 was the template for $h t z 1::$ LEU2, rad6::LEU2, rad52::LEU2, and $x r s 2::$ LEU2 cassettes. Primers are listed in Table 2. Cassettes were amplified with Platinum Taq DNA polymerase High Fidelity (Invitrogen), purified with a PureLink ${ }^{\mathrm{TM}}$ gel extraction kit (Invitrogen), and used for yeast transformation according to the LiAc/PEG protocol (Gietz and Woods, 2002). Disruption was confirmed by PCR and restriction analysis of purified genomic DNA from transformant yeast colonies selected in synthetic media lacking uracil or leucine.

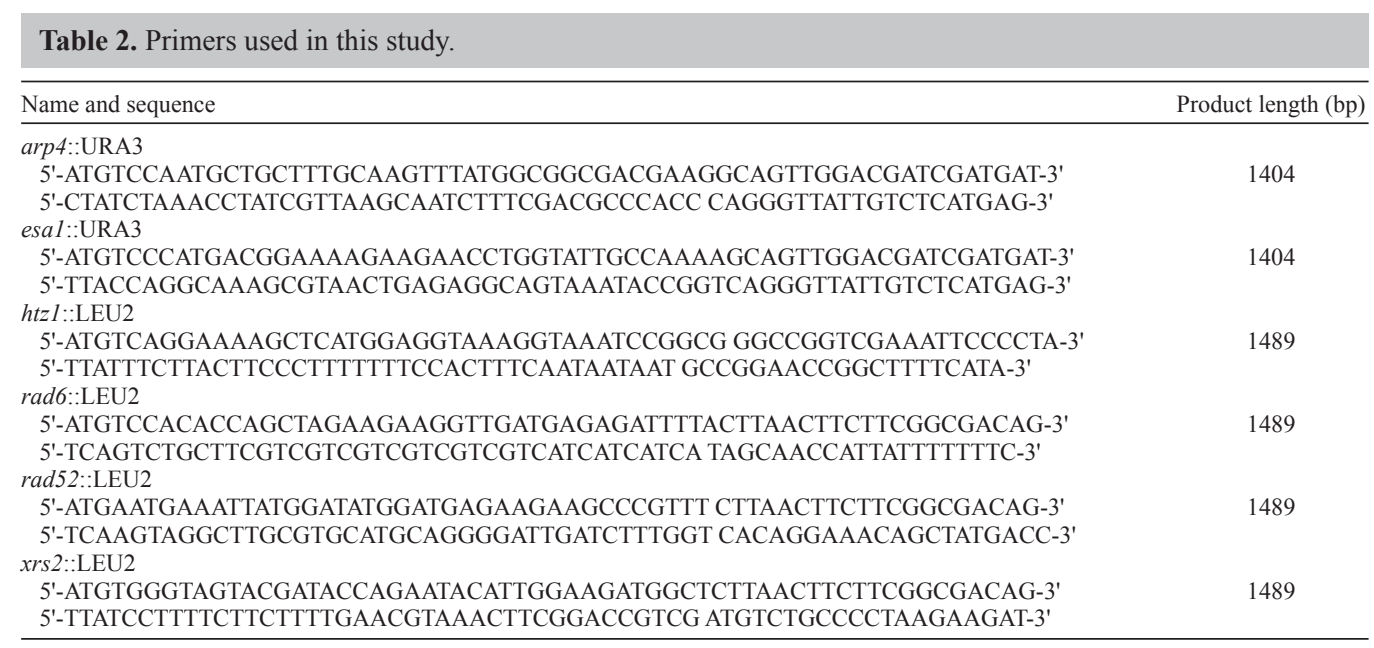

\section{Cell cycle analysis}

Cells were monitored by distribution in G1/S (unbudded), S (small-budded), and G2/M (large-budded) phase. About 200 to 300 cells (treated with 5-FU or untreated controls) were counted in a Neubauer chamber. Large-budded cells were defined as those in which the bud was $>50 \%$ the size of the mother cell (Cardone et al., 2006). Graphics represent the average of three independent experiments.

\section{Analysis of 5-FU in DNA}

Cells were lysed with lyticase (Sigma) and genomic DNA was isolated using 10\% SDS, $5 \mathrm{M} \mathrm{KOAc}$, and $70 \%$ ethanol. DNA $(1.5 \mu \mathrm{g})$ was digested at $37^{\circ} \mathrm{C}$ for $3 \mathrm{~h}$ with $1 \mathrm{U}$ uracil DNA glycosylase (UDG) and $1 \mathrm{U}$ human AP endonuclease (APE1) in buffer containing $50 \mathrm{mM}$ Tris$\mathrm{HCl}, \mathrm{pH} 7.5,1 \mathrm{mM}$ EDTA, $50 \mathrm{mM} \mathrm{NaCl}$, and $10 \mathrm{mM} \mathrm{MgCl}_{2}$. Reaction products were separated on a $0.8 \%$ agarose gel and stained with ethidium bromide. Graphics represent the average of three independent experiments. Images were acquired with a Kodak Gel Logic 200 Imaging System and DNA band intensity was measured with the Kodak Molecular Imaging Software. 


\section{RESULTS AND DISCUSSION}

Chromatin structure affects DNA-related processes such as replication, transcription, and recombination (Altaf et al., 2007). More recently, its influence on DNA repair has been described (Ataian and Krebs, 2006; Escargueil et al., 2008). Since most antineoplasic drugs act by inducing DNA damage, efficient repair of these lesions may influence clinical response (Ding et al., 2006). Given that chromatin structure modulates access of repair proteins to the site of damage, chromatin remodelers are emerging as a promising target for cancer therapy (Escargueil et al., 2008).

5 -FU is an antimetabolite antitumor drug whose cytotoxicity is largely based on creating DNA damage; it has been employed to treat carcinomas arising in the gastrointestinal tract, ovary, breast, head, neck, and esophagus. Several potential modes of action have been proposed, but the participation of chromatin modifiers in 5-FU toxicity has not been described.

\section{Strains deficient in chromatin remodeling and histone acetyltransferases (HATs) presented sensitivity towards 5-FU}

To investigate the importance of chromatin remodeling factors for 5-FU cytotoxicity, we screened a large panel of $S$. cerevisiae strains with deletion mutations in genes with roles in canonical histones, non-histone proteins related to the high-mobility group (HMG), ATP-dependent chromatin remodeling (CR), and covalent post-translational modifications by HAT, histone deacetylases, histone ubiquitinization, histone methylation, and histone demethylation. Strains deficient in HMG, CR, and some HATs were more sensitive to 5-FU in comparison to the wild-type (WT) strain (Figure 1).

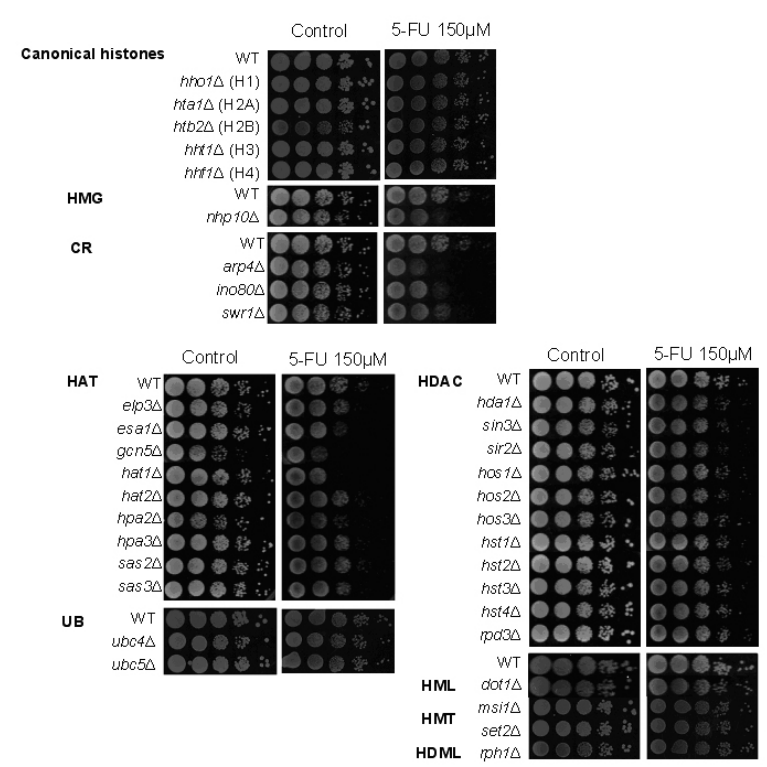

Figure 1. 5-Fluorouracil (5-FU) sensitivity in Saccharomyces cerevisiae-deficient strains. Logarithmic cultures were serially dilluted 10 -fold and spotted onto YPD medium plates with 5-FU. HMG = high mobility group; $\mathrm{CR}=\mathrm{ATP}$-dependent chromatin remodeling; HAT $=$ histone acetyltransferase; $\mathrm{UB}=$ ubiquitin; HDAC $=$ histone deacetylase; $\mathrm{HML}=$ histone methylase; $\mathrm{HMT}=$ histone methyltransferase; $\mathrm{HDML}=$ histone demethylase. 
The data presented in Figure 1 show that strains deficient in Nhp10 (an HMG-1-like protein), Arp4, Ino80, or Swr1 (ATP-dependent CR proteins) were more sensitive to 5-FU than the WT control. Interestingly, all of these proteins belong to the INO80 subfamily, which is composed of the INO80 and SWR1 complexes. The INO80 complex slides nucleosomes into DNA regions to promote chromatin relaxation and includes several proteins such as Ino80, Arp4, and Nhp10 (for review, see Bao and Shen, 2007). The Ino80 subunit is a functional ATPase and nucleosome spacing factor with 3'- to 5'-DNA helicase activity in vitro (van Attikum and Gasser, 2005a). Arp4 (actin-related protein 4) is present in chromatin-modifying complexes such as INO80, SWR1, and NuA4 and can bind histones, modified histones, and nucleosomes, and possesses ATP-binding activity (Hargreaves and Crabtree, 2011). Nhp10 is a subunit of the INO80 complex that can bind to DNA or nucleosomes; its absence leads to reduced binding activity by the INO80 complex, but the complex retains the ability to mobilize nucleosomes (Bao and Shen, 2007). Nhp10 is also necessary for the specific interaction of INO80 at DSB sites in response to DNA damage (Morrison et al., 2004). The SWR1 complex is composed of 14 polypeptides including Swr1, Vps71, Act1, and Arp4 (for review, see Bao and Shen, 2007); the major function of this complex is to exchange histone H2A in nucleosomes for its variant Htz1 (H2AZ in mammals), replacing the preexisting $\mathrm{H} 2 \mathrm{~A}-\mathrm{H} 2 \mathrm{~B}$ dimer with Htz1-H2B (Mizuguchi et al., 2004). This substitution of canonical histones with histone variants generates a structurally and functionally distinct region in the chromatin (Henikoff and Ahmad, 2005).

5-FU also sensitized strains deficient in Esa1, Gen5, and Hat1 (Figure 1). All of these proteins are involved in DSB recombinational repair (Tamburini and Tyler, 2005; Ataian and Krebs, 2006). Esa1 is the catalytic subunit of the NuA4 HAT complex and mutations in this protein reduce recruitment of INO80 and SWR1 to damage sites (Downs et al., 2004). It is required for cell cycle progression (Doyon and Côté, 2004) and it preferentially acetylates H4 histone (Clarke et al., 1999) within coding regions, suggesting a role in global acetylation. Gen5 is a nuclear HAT that belongs to the Ada and SAGA complexes; it preferentially acetylates $\mathrm{H} 3$ histone and plays important roles in histone acetylation during transcription activation (Clarke et al., 1999). Gcn5 also has a separate and independent role in nucleotide excision repair and is essential for efficient repair of UV damage at repressed loci (Yu et al., 2005). It is responsible for most of the post-UV increase in histone acetylation at lysines 9/14; these are seen throughout much of the yeast genome and are not related to transcriptional activation. Hat1 is an HAT-type B; it acetylates cytoplasmic non-chromatin-associated histones that will be transported to the nucleus. At the nucleus, it may play a role in chromatin assembly with Hif1, a histone H3/H4 chaperone (Qin and Parthum, 2006; Benson et al., 2007); it is also important for telomeric silencing and the Hat1 mutant is deficient in recombination repair (Benson et al., 2007).

\section{5-FU effects on the interaction between chromatin remodeling factors}

Based on the preliminary data from the 5-FU sensitivity screen (Figure 1), the most sensitive strains were selected to investigate the cellular effects of these deletions. The cytotoxic and cytostatic activities of 5-FU were evaluated by the PQDT method. The arp $4 \Delta$ and ino80 4 CR-single mutants were sensitive to 5-FU, although deletion of Arp4 resulted in more pronounced toxicity (Figure 2A). The WT strain presented a potent and similar cytostatic 
activity for all 5-FU concentrations tested. In contrast, strains defective in Arp4 or Ino80 presented stronger, dose-dependent cytostatic activity (Figure 2B). The esa1A, hat1A, and gcn5 HAT single-mutants were sensitive to 5-FU (Figure 2C) and showed a strong cytostatic doseresponse in esalA and hat14 (Figure 2D).

A

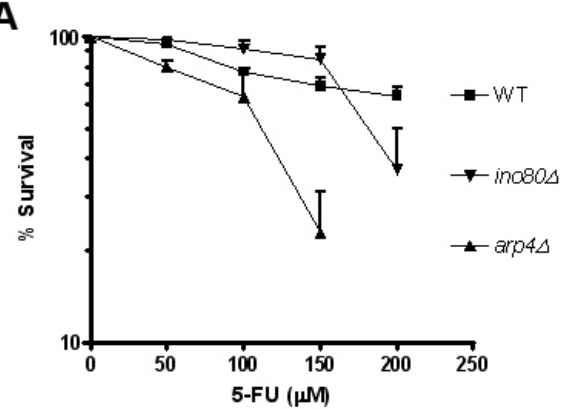

C

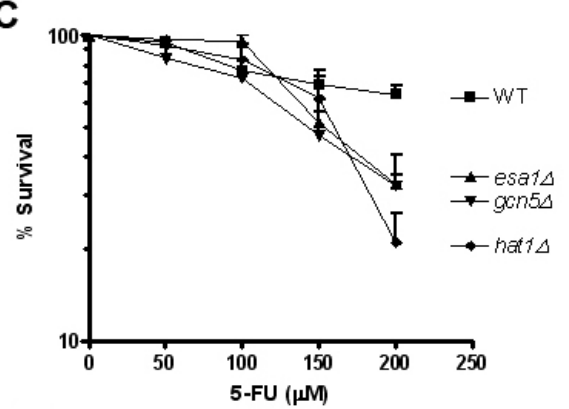

B

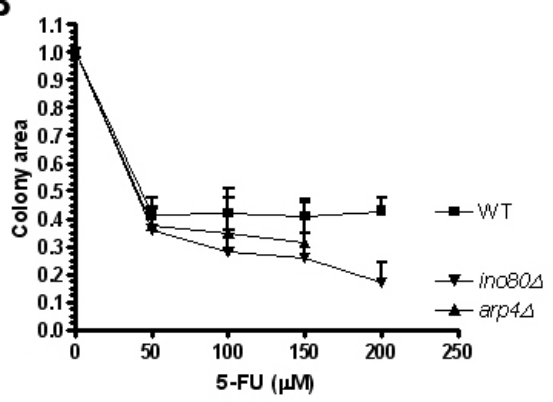

D

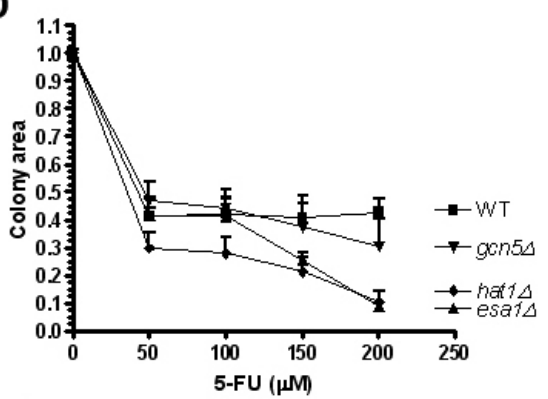

Figure 2. Cytotoxicity (A, C) and cytostatic (B, D) effect of 5-fluorouracil (5-FU) in Saccharomyces cerevisiaedeficient strains. Data are reported as means \pm standard deviation for three independendent experiments.

The possible interaction between chromatin remodeling factors in 5-FU toxicity was evaluated by constructing double-mutants. Deficiencies in CR/HAT, such as arp4AesalA and hat1 1 arp $4 \Delta$, did not produce sensitivity to 5-FU (Figure 3A and B) and showed a cytostatic effect similar to WT (Figure 3C and D). Surprisingly, the HAT double-mutant hat1 1 esa14 was not sensitive to 5-FU (Figure 3E) and exhibited a cytostatic effect similar to WT (Figure 3F).

Since we observed that Swr1 was important for 5-FU cytotoxicity, we investigated the possible role of the histone variant Htzl and its interactions with CRs and HATs. Htz1 incorporation into nucleosomes prevents spreading of silent chromatin into euchromatin regions (Raisner and Madhani, 2006). It also ensures efficient initiation of transcription and cooperates with other components to repel silencing factors (Campos and Reinberg, 2009). The data presented in Figure 4A, B, and C show that defects in Htz1 did not result in significant sensitivity to 5-FU, and that the double-mutants involving $h t z 1 \Delta$ and $\operatorname{arp} 4 \Delta$, esa $1 \Delta$ or hat14 showed no sensitivity to this drug in comparison to WT. The single- and all doublemutants involving Htz1 showed a cytostatic effect similar to WT (Figure 4D, E and F). 

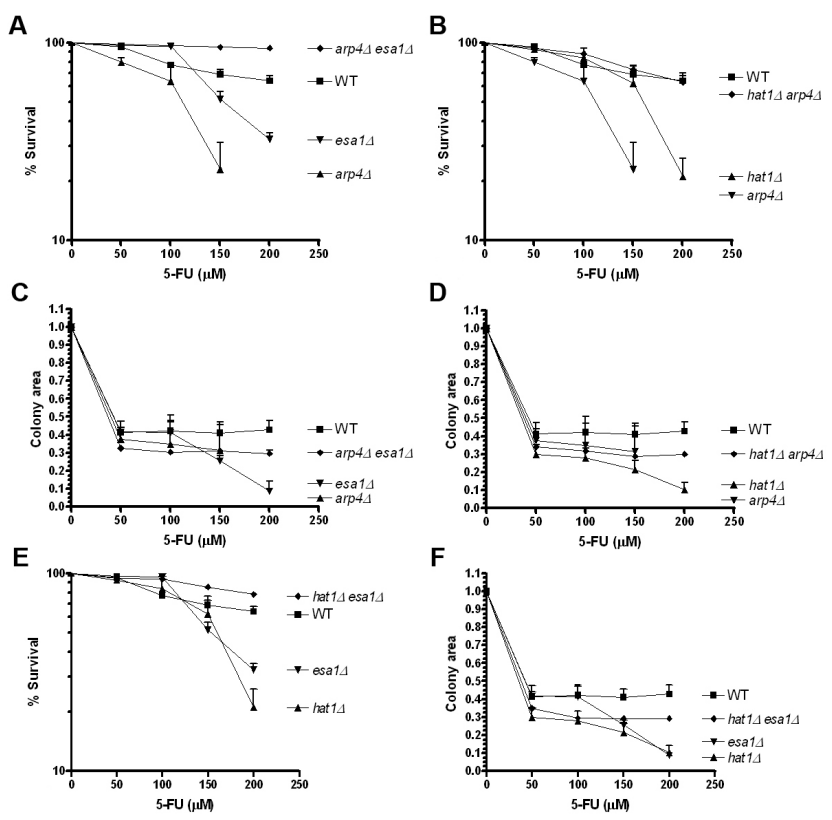

Figure 3. 5-Fluorouracil (5-FU) sensitivity (A, C and $\mathbf{E})$ and cytostatic (B, D and $\mathbf{F})$ activity in yeast defective strains in chromatin remodeling double-mutants. Data are reported as means \pm standard deviation for three independent experiments.
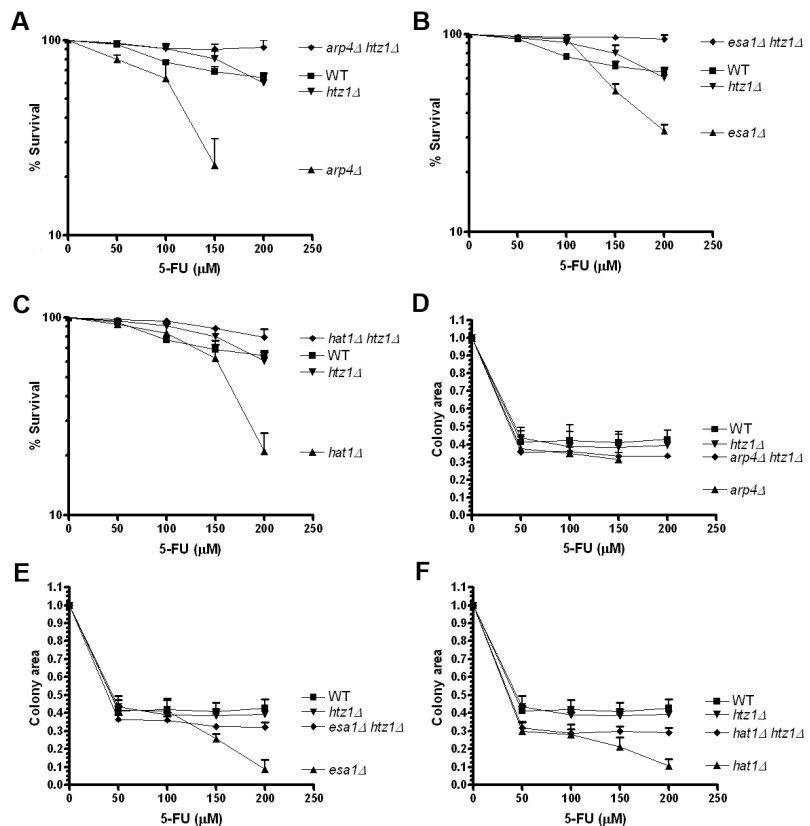

Figure 4. Cytotoxicity (A, C and $\mathbf{E})$ and cytostatic $(\mathbf{B}, \mathbf{D}$ and $\mathbf{F})$ effect of 5-fluorouracil (5-FU) in Saccharomyces cerevisiae-deficient strains involving the histone variant Htzl. Data are reported as means \pm standard deviation for three independent experiments. 


\section{5-FU induces cell cycle arrest in chromatin remodeling-deficient strains}

The data presented in Figures 2, 3, and 4 indicate that 5-FU has potent cytostatic activity; thus, we investigated the cell cycle distribution in chromatin remodeling-deficient strains. After 5-FU exposure, WT, esal 1 , and $h t z 1 \Delta$ strains showed an increase in the S-phase population, while strains defective in Arp4, Hat1, Ino80, and Swr1, as well as the double-mutants

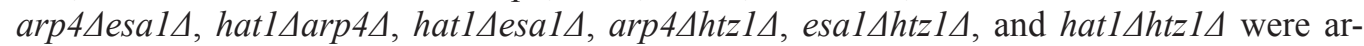
rested in G2/M (Figure 5). The single-mutants were more sensitive and presented pronounced cytostatic activity in response to 5-FU, leading to G2/M arrest, except esald, probably because of its role in cell cycle progression. Interestingly, although the double-mutants did not exhibit cytotoxic and cytostatic responses to 5-FU, they did exhibit G2/M arrest.
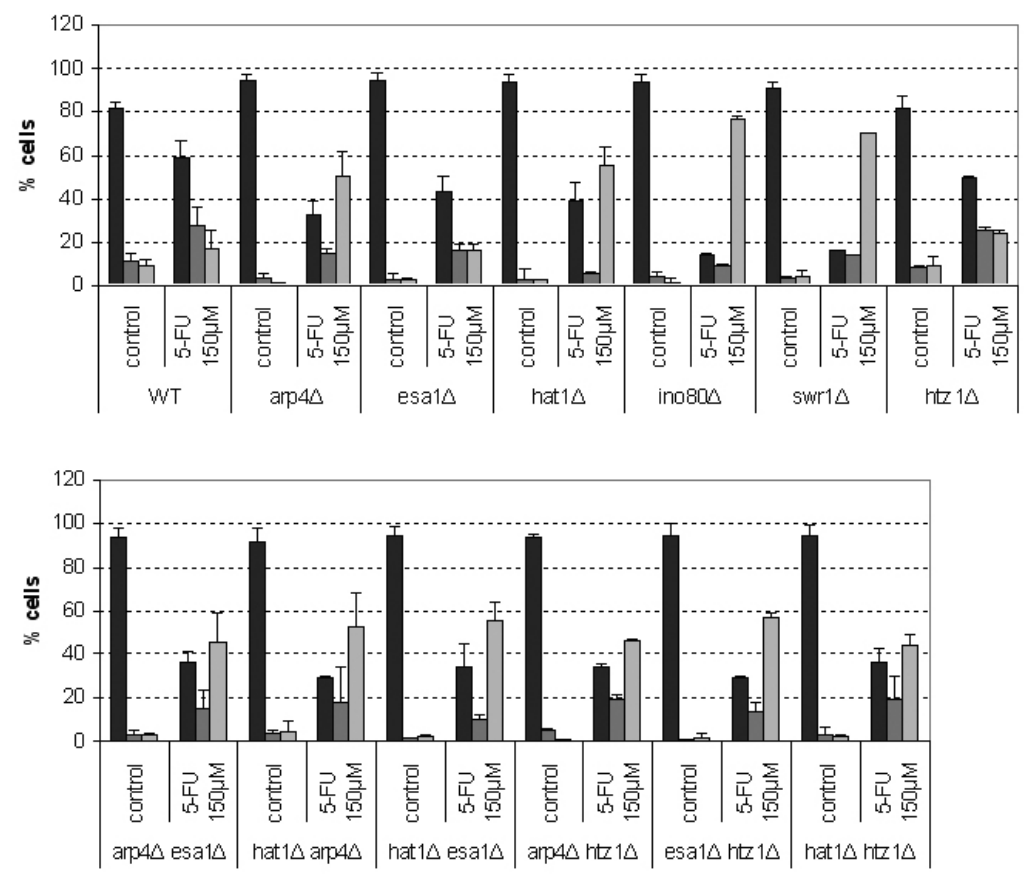

Figure 5. Cell cycle analysis. Distribution of G1/S (black columns), S (gray columns) and G2/M (light-gray columns) cells in single- and double-mutants after 5-fluorouracil (5-FU) exposure. Data are reported as means \pm standard deviation for three independent experiments.

\section{Deficiencies in chromatin remodeling did not interfere in the excision of 5-FU misincorporated into DNA}

Considering that chromatin remodelers alter chromatin structure to allow access of repair proteins, this aspect of our study aimed to investigate if strains deficient in CR, HATs, and Htz1 were able to repair 5-FU lesions. 5-FU is an antimetabolite that may be misincorporated into DNA; it is removed from DNA by the uracil glycosylase Ung1 (UDG in human) via base 
excision repair (BER) (Matuo et al., 2010). The resulting AP site is processed by Apn1 (APE1 in humans) and, if not properly repaired, it is converted to SSB and DSB. Several chromatin remodeling mutants were exposed to 5-FU, the DNA extracted, and digested with UDG and APE1. In the presence of misincorporated 5-FU, DNA breaks are generated, thus reducing the molecular weight of DNA on denaturing agarose gels. Our data showed that defects in CR, HATs, and Htz1 did not influence 5-FU excision from DNA, since there was no difference between digested and undigested DNA migration (Figure 6). Therefore, 5-FU misincorporated into DNA is effectively removed by BER enzymes in chromatin remodeling-defective strains, including the CR/HAT and HAT double-mutants.

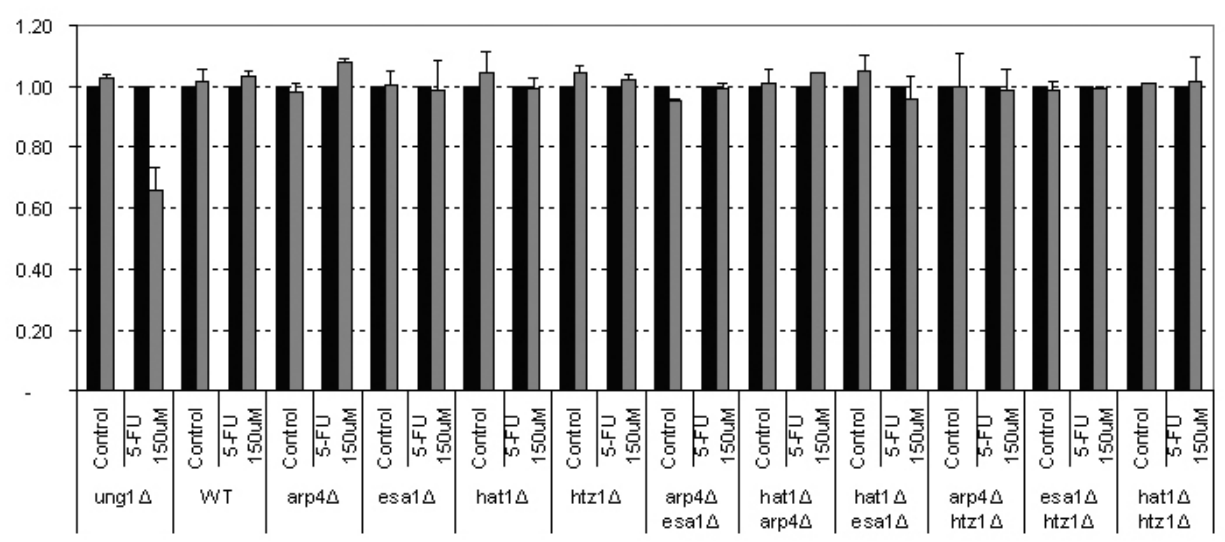

Figure 6. Presence of 5-fluorouracil (5-FU) and abasic sites in yeast genome DNA. DNA from strains treated with or without 5-FU were digested with uracil DNA glycosylase and APE1, and fractionated by agarose gel electrophoresis. The strain ung $1 \Delta$ exposed to 5-FU was employed as a positive control, since this strain accumulates fluoronucleotides, and when its DNA is digested with both base excision repair enzymes, 5-FU is removed and double-strand break may be formed, which decrease the amount of DNA band in comparison to control without enzymes. The graph represents the relative value of DNA band quantified by the Kodak Molecular Imaging Software . Black columns $=$ DNA without digestion; gray columns $=$ DNA digested with enzymes. Data are reported as means \pm standard deviation for three independent experiments.

\section{Chromatin modifiers influence the repair of 5-FU by homologous recombination (HR)}

Since we observed that deficiencies in CR, HATs, and Htz1 did not interfere with 5-FU removal from DNA by BER, the influence of chromatin remodeling on other DNA repair pathways was investigated. 5-FU lesions are processed by several DNA repair pathways, such as BER, mismatch repair, post-replication repair (PRR) and HR (Matuo et al., 2010). HR repairs DSBs and is the prevalent mechanism in yeast (Aylon and Kupiec, 2004). Considering the observed G2/M arrest in strains deficient in chromatin modifiers, the participation of chromatin remodelers in HR repair was investigated by employing double-mutants. Doublemutants of Rad52 with HMG, CR, and HAT, as well as Xrs2 with the same chromatin modifiers were constructed. Xrs2 acts with Mre11 and Rad50 (MRX complex) at the initial steps of $\mathrm{HR}$, recognizing and processing the broken ends, while Rad52 works in the intermediate steps, stimulating strand exchange by facilitating Rad51 binding to single-stranded DNA (Ataian

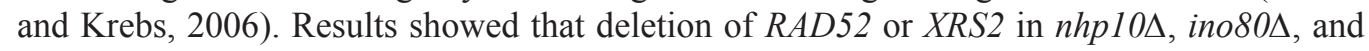


swr $1 \Delta$ strains increased 5-FU sensitivity in comparison to the single-mutants, but not in the HAT-deficient strains gcn5s and hat $1 \Delta$ (Figures 7 and 8). Therefore, both HATs may work together in the HR pathway. These data suggest that HMG and CRs are important promoters of chromatin relaxation at DSB damage sites during HR repair, and HATs may contribute to this process.

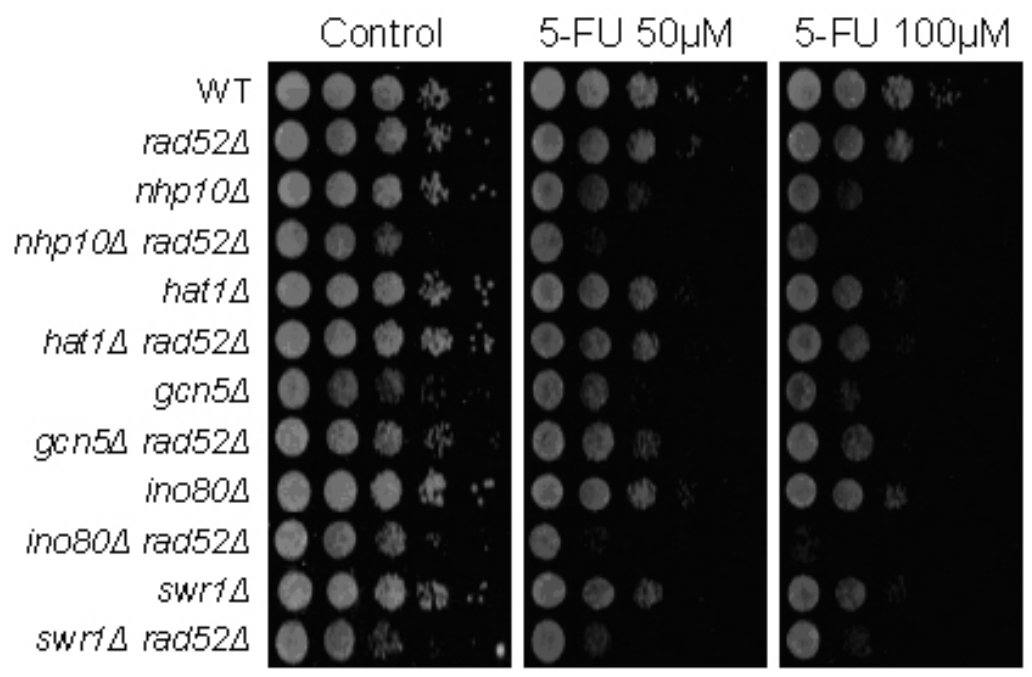

Figure 7. Participation of chromatin remodelers in homologous recombination repair of 5-fluorouracil (5-FU) lesions. Sensitivity was evaluated in single- and double-mutants involving rad52 $\Delta$ and high-mobility group nonhistone protein, ATP-dependent chromatin remodeling or histone acetyltransferase.

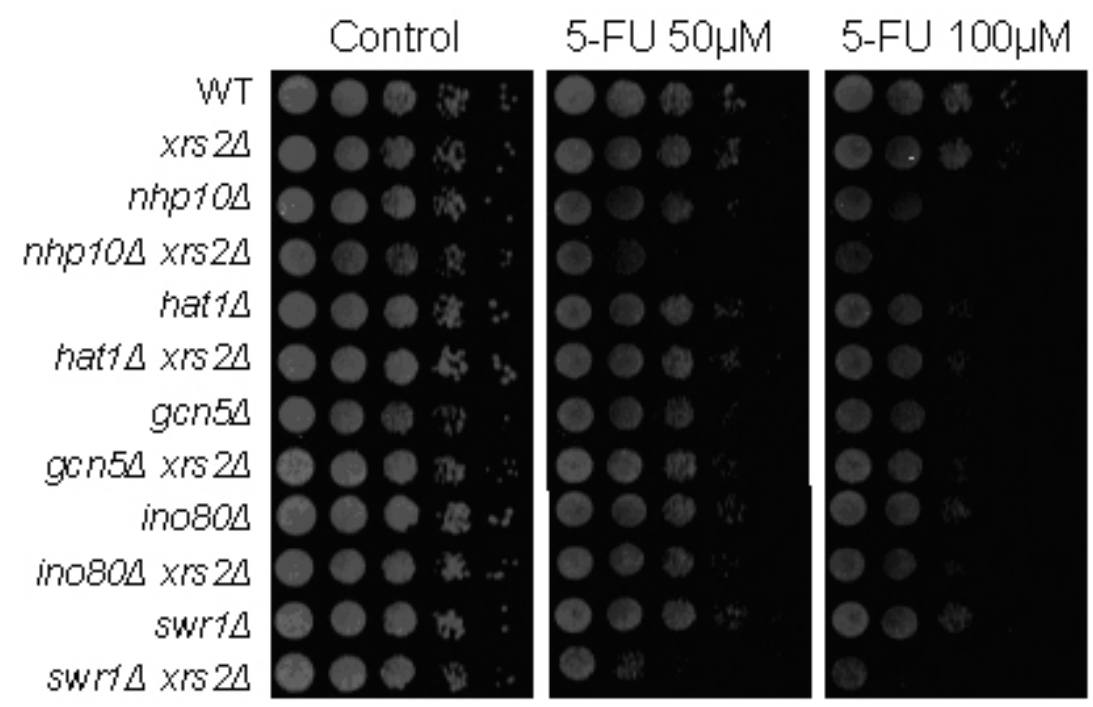

Figure 8. Participation of chromatin remodelers in homologous recombination repair of 5-fluorouracil (5-FU) lesions. Sensitivity was evaluated in single- and double-mutants involving $x r s 2 \Delta$ and high-mobility group nonhistone protein, ATP-dependent chromatin remodeling or histone acetyltransferase. 
Indeed, previous studies have reported that several chromatin modifiers are involved in DSB repair by HR (Tamburini and Tyler, 2005; Ataian and Krebs, 2006). At the lesion site, the Mec1 and Tel1 enzymes phosphorylate histone H2AX at serine-129 (referred as $\gamma \mathrm{H} 2 \mathrm{AX}$ ). Mec1, through its binding partner Ddc2 and Tel1 via interaction with the Mre11/Rad50/Xrs2 complex, recruits multiple-chromatin-modifying complexes that allow DNA repair factors access to the lesion (van Attikum and Gasser, 2005b). $\gamma \mathrm{H} 2 \mathrm{AX}$ recruits the HAT complex NuA4 (yeast homologue of mammalian TIP60) via its Arp4 subunit and Nhp10 facilitates Arp4$\gamma \mathrm{H} 2 \mathrm{AX}$ interaction (van Attikum and Gasser, 2005a). Esal (catalytic component of NuA4) acetylates the N-terminal tail of $\mathrm{H} 4$ histone surrounding the break site (van Attikum and Gasser, 2005a; Loizou et al., 2006); then, INO80 and SWR1 CR complexes, as well as HATs Hat1 and Gcn5, are recruited to facilitate efficient repair of DNA damage (Downs et al., 2004; Qin and Parthum, 2006; Bao and Shen, 2007). The INO80 complex promotes the removal or nucleosome slide to facilitate processing of newly broken DNA ends, which enables conversion of double-strand DNA ends into 3'-single-strand overhangs by the MRX complex (van Attikum et al., 2005a) and controls the rate at which Rad51 displaces replication protein A during HR (Ataian and Krebs, 2006; Bao and Shen, 2007). The SWR1 complex is also recruited for DNA repair; it possesses ATP-dependent CR activities, which deposit the histone variant Htz1 (homolog of H2AZ) in specific locations in vivo and exchange modified histones after repair has been completed (Loizou et al., 2006). The histone variant Htz1 has roles in transcriptional activation, antagonization of gene-silencing and chromosome stability (Raisner and Madhani, 2006), and when incorporated at DSB sites, it contributes to local chromatin relaxation. Other histone modifications are also important for DNA repair by HR (van Attikum and Gasser, 2005b), such as acetylation by Hat1 and Gen5 (Ataian and Krebs, 2006). Hat1 is recruited at DSB after H2AX phosphorylation concomitant with Rad52, which suggests that Hat1 may act facilitating DNA repair by HR and/or act in the restoration of chromatin structure following recombinational repair, since Hat 1 catalyzes acetylation of amino-terminal tails of newly synthesized histones (Qin and Parthum, 2006). Gen5 is required for transcriptional activation and separately participates in the nucleotide excision repair of ultraviolet light-induced DNA lesions (Yu et al., 2005).

\section{Chromatin remodeling interferes in 5-FU repair by PRR}

5-FU lesions are also repaired by PRR (Matuo et al., 2010). In order to investigate the influence of chromatin modifiers in PRR, we constructed double mutants of Rad6 with HMG, $\mathrm{CR}$, and HATs. Rad6p is a ubiquitin-conjugating enzyme that exists in a complex with Rad18. Rad6-Rad18 form a stable complex with single-stranded DNA (Broomfield et al., 2001) and mediate ubiquitin conjugation of the DNA polymerase processivity factor PCNA (proliferating cell nuclear antigen), which promotes replication through DNA lesions by mutagenic or error-free translesion synthesis (TLS) (Minesinger and Jinks-Robertson, 2005; Prakash et al., 2005). Mono-ubiquitinylation of PCNA mediates error-prone TLS, while poly-ubiquitinylation triggers the error-free pathway. TLS occurs in S-phase to ensure replication completion, but also operates in G2/M (Karras and Jentsch, 2010). Our data demonstrated that deletion of RAD6 in $n h p 10 \Delta$, ino $80 \Delta$, and swr1 $1 \Delta$ increased sensitivity to 5-FU in comparison to the single-mutants, but the same was not observed for strains defective in HATs such as hat $1 \Delta$ and gcn $5 \Delta$ (Figure 9). 


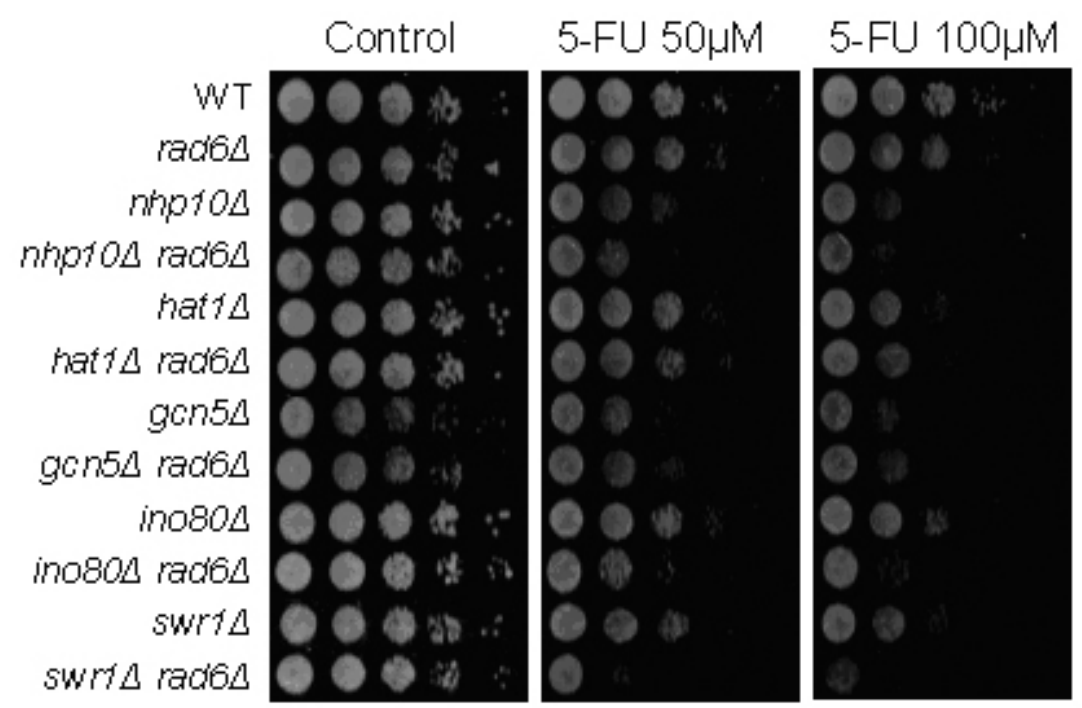

Figure 9. Involvement of chromatin modifiers in post-replication repair of 5-fluorouracil (5-FU). Sensitivity was investigated in single- and double-mutants combining rad64 and high-mobility group non-histone protein, ATPdependent chromatin remodeling or histone acetyltransferase.

Few studies have investigated the participation of chromatin modifiers in PRR. Besides the activity of INO80 in HR, it also plays roles in DNA damage tolerance during replication: this complex binds to replication forks during S-phase and allows access of the RAD6 and RAD51 pathways to process obstructed replication forks. INO80 regulates ubiquitination of PCNA and Rad51-mediated processing of recombination intermediates at blocked replication forks by allowing proper recruitment of Rad18 and Rad51 (Falbo et al., 2009).

\section{CONCLUDING REMARKS}

These data demonstrate that some ATP-dependent CR factors and specific HATs may influence 5-FU cytotoxicity, probably due to interference with DNA repair. Ino80 and Swr1 CR are directly recruited to DNA damage and lead to chromatin relaxation, which facilitates access of HR and PRR proteins to 5-FU lesions, as well as Nhp10. Deficiencies in Rad52 and Xrs2 (HR) or Rad6 (PRR), combined with Ino80, Swr1, and Nhp10 yielded increased sensitivity to 5-FU. However, deficiencies in Gen5 and Hat1 combined with defects in HR and PRR did not potentiate 5-FU cytotoxicity, possibly because they work in a common pathway. Figure 10 summarizes the participation of chromatin remodeling in 5-FU lesion repair by HR and PRR.

Chromatin structure influences many biological processes and may modulate DNA repair, which then directly interferes in the activity of antineoplasic drugs. Thus, identification of new targets that improve the efficacy of anticancer agents can provide new possibilities for cancer treatment and possibly overcome drug resistance and side effects. 


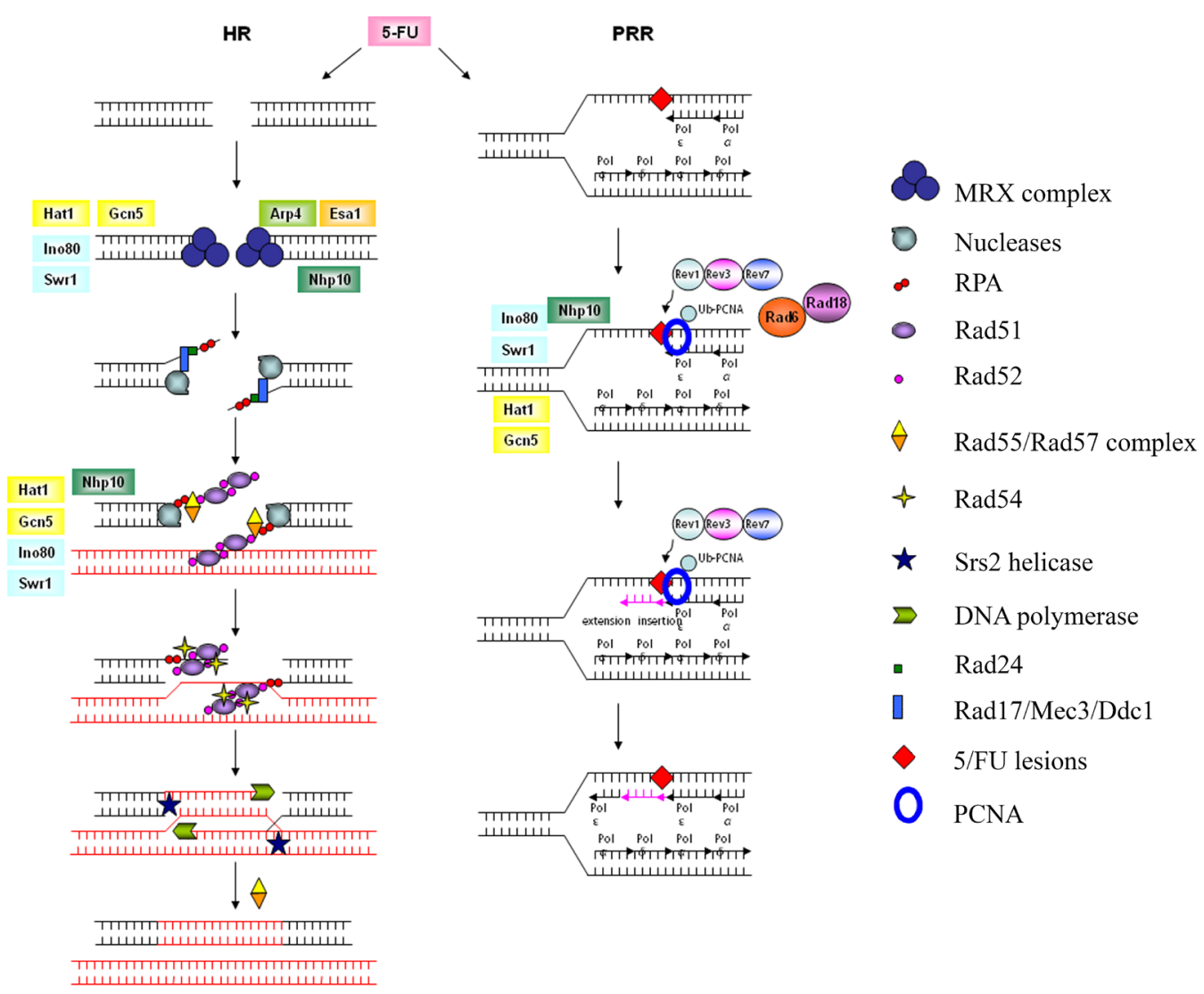

Figure 10. Chromatin remodeling and DNA repair of 5-fluorouracil (5-FU) lesions. 5-FU may induce different types of DNA damage, such as double-strand breaks (DSB) and replication inhibition, which are repaired by homologous (HR) or post-replication repair (PRR), respectively. Several types of high-mobility group non-histone protein, ATP-dependent chromatin remodeling and histone acetyltransferase participate in different steps of HR and PRR. In HR pathway (left side): after DSB formation, the Mre11/Rad50/Xrs2 (MRX complex) recognize the damaged DNA. At this step, several chromatin modifiers (Arp4, Esa1, Nhp10, Ino80, Swr1, Gcn5, and Hat1) may act. Nucleases bind to DNA and generate single-stranded DNA tails, which are coated by the replication protein A (RPA). Then, Rad51 filament is formed, displacing RPA from resected DNA. Rad52 and Rad55/Rad57 complex mediate filament formation, and Rad54 may also participate at this step. During this step, chromatin remodelers may work. Concomitantly, the filament search for homologous sequences and when they are found, the resection ceases and Rad51 filament is disassembled, mediated by Srs2 helicase. DNA polymerase restore the DNA sequency followed by religation. Rad24; Rad17/Mec3/Ddc1 (HR pathway modified from Aylon and Kupiec, 2004). In PRR pathway (right side): 5-FU lesions may stall replication forks. DNA pol $\delta$ and pole replicate genomic DNA, but they are unable to bypass lesions. In response to stalled replication fork, Rad6/Rad 18 complex ubiquitinates proliferating cell nuclear antigen (PCNA), which causes the dissociation of DNA replication polymerases and the association of damage bypass polymerases: pol zeta (Rev3/Rev7) associated to Rev1. At this step, chromatin modifiers (Nhp10, Ino80, Swr1, Hat1, and Gcn5) may act. Pol zeta or Rev1 inserts a nucleotide in opposite to the lesion and then pol zeta extends the DNA. The lesion bypass complex (Rev3/Rev7 and Rev1) dissociates from the template and normal replication polymerases reassociate to continue replication (PRR pathway adapted from Gan et al., 2008). 


\section{ACKNOWLEDGMENTS}

We thank Dr. Lisiane Meira for providing the strains, Dr. Dinara Moura and Dr. Jacqueline Cardone for helping construct the double mutants, and Dr. Temenouga N. Guecheva and Dr. Raymond Waters for critical reading of the manuscript. Research supported by research grants from Conselho Nacional de Desenvolvimento Científico e Tecnológico (CNPq), Fundação de Coordenação de Aperfeiçoamento de Pessoal de Nível Superior (CAPES/ COFECUB; grants \#583/07), GENOTOX-Royal Institute, Biotechnology Center UFRGS and PRONEX/FAPERGS/CNPq (\#10/0044-3). R. Matuo and F.G. Sousa have fellowships from CNPq and CAPES, respectively, and are postgraduate students at UFRGS.

\section{REFERENCES}

Altaf M, Saksouk N and Cote J (2007). Histone modifications in response to DNA damage. Mutat. Res. 618: 81-90.

Ataian Y and Krebs JE (2006). Five repair pathways in one context: chromatin modification during DNA repair. Biochem. Cell Biol. 84: 490-504.

Aylon Y and Kupiec M (2004). New insights into the mechanism of homologous recombination in yeast. Mutat. Res. 566: 231-248.

Bao Y and Shen X (2007). INO80 subfamily of chromatin remodeling complexes. Mutat. Res. 618: 18-29.

Benson LJ, Phillips JA, Gu Y, Parthun MR, et al. (2007). Properties of the type B histone acetyltransferase Hat1: H4 tail interaction, site preference, and involvement in DNA repair. J. Biol. Chem. 282: 836-842.

Broomfield S, Hryciw T and Xiao W (2001). DNA postreplication repair and mutagenesis in Saccharomyces cerevisiae. Mutat. Res. 486: 167-184.

Campos EI and Reinberg D (2009). Histones: annotating chromatin. Annu. Rev. Genet. 43: 559-599.

Cardone JM, Revers LF, Machado RM, Bonatto D, et al. (2006). Psoralen-sensitive mutant pso9-1 of Saccharomyces cerevisiae contains a mutant allele of the DNA damage checkpoint gene MEC3. DNA Repair 5: 163-171.

Clarke AS, Lowell JE, Jacobson SJ and Pillus L (1999). Esa1p is an essential histone acetyltransferase required for cell cycle progression. Mol. Cell Biol. 19: 2515-2526.

Ding J, Miao ZH, Meng LH and Geng MY (2006). Emerging cancer therapeutic opportunities target DNA-repair systems. Trends Pharmacol. Sci. 27: 338-344.

Downs JA, Allard S, Jobin-Robitaille O, Javaheri A, et al. (2004). Binding of chromatin-modifying activities to phosphorylated histone H2A at DNA damage sites. Mol. Cell 16: 979-990.

Doyon Y and Côté J (2004). The highly conserved and multifunctional NuA4 HAT complex. Curr. Opin. Genet. Dev. 14: $147-154$

Escargueil AE, Soares DG, Salvador M, Larsen AK, et al. (2008). What histone code for DNA repair? Mutat. Res. 658: 259-270.

Falbo KB, Alabert C, Katou Y, Wu S, et al. (2009). Involvement of a chromatin remodeling complex in damage tolerance during DNA replication. Nat. Struct. Mol. Biol. 16: 1167-1172.

Gan GN, Wittschieben JP, Wittschieben BO and Wood RD (2008). DNA polymerase zeta (pol zeta) in higher eukaryotes. Cell Res. 18: 174-183.

Gangaraju VK and Bartholomew B (2007). Mechanisms of ATP dependent chromatin remodeling. Mutat. Res. 618: 3-17.

Gietz RD and Woods RA (2002). Transformation of yeast by lithium acetate/single-stranded carrier DNA/polyethylene glycol method. Methods Enzymol. 350: 87-96.

Hargreaves DC and Crabtree GR (2011). ATP-dependent chromatin remodeling: genetics, genomics and mechanisms. Cell Res. 21: 396-420.

Henikoff S and Ahmad K (2005). Assembly of variant histones into chromatin. Annu. Rev. Cell Dev. Biol. 21: 133-153.

Huertas D, Sendra R and Munoz P (2009). Chromatin dynamics coupled to DNA repair. Epigenetics 4: 31-42.

Karras GI and Jentsch S (2010). The RAD6 DNA damage tolerance pathway operates uncoupled from the replication fork and is functional beyond S phase. Cell 141: 255-267.

Kufe DW and Major PP (1981). 5-Fluorouracil incorporation into human breast carcinoma RNA correlates with cytotoxicity. J. Biol. Chem. 256: 9802-9805.

Kufe DW, Major PP, Egan EM and Loh E (1981). 5-Fluoro-2'-deoxyuridine incorporation in L1210 DNA. J. Biol. Chem. 256: 8885-8888. 
Loizou JI, Murr R, Finkbeiner MG, Sawan C, et al. (2006). Epigenetic information in chromatin: the code of entry for DNA repair. Cell Cycle 5: 696-701.

Matuo R, Sousa FG, Escargueil AE, Grivicich I, et al. (2009). 5-Fluorouracil and its active metabolite FdUMP cause DNA damage in human SW620 colon adenocarcinoma cell line. J. Appl. Toxicol. 29: 308-316.

Matuo R, Sousa FG, Escargueil AE, Soares DG, et al. (2010). DNA repair pathways involved in repair of lesions induced by 5-fluorouracil and its active metabolite FdUMP. Biochem. Pharmacol. 79: 147-153.

Minesinger BK and Jinks-Robertson S (2005). Roles of RAD6 epistasis group members in spontaneous polzeta-dependent translesion synthesis in Saccharomyces cerevisiae. Genetics 169: 1939-1955.

Mizuguchi G, Shen X, Landry J, Wu WH, et al. (2004). ATP-driven exchange of histone H2AZ variant catalyzed by SWR1 chromatin remodeling complex. Science 303: 343-348.

Morrison AJ, Highland J, Krogan NJ, Arbel-Eden A, et al. (2004). INO80 and gamma-H2AX interaction links ATPdependent chromatin remodeling to DNA damage repair. Cell 119: 767-775.

Noordhuis P, Holwerda U, Van der Wilt CL, van Groeningen CJ, et al. (2004). 5-Fluorouracil incorporation into RNA and DNA in relation to thymidylate synthase inhibition of human colorectal cancers. Ann. Oncol. 15: 1025-1032.

Osley MA, Tsukuda T and Nickoloff JA (2007). ATP-dependent chromatin remodeling factors and DNA damage repair. Mutat. Res. 618: 65-80.

Poletto NP, Rosado JO and Bonatto D (2009). Evaluation of cytotoxic and cytostatic effects in Saccharomyces cerevisiae by poissoner quantitative drop test. Basic Clin. Pharmacol. Toxicol. 104: 71-75.

Prakash S, Johnson RE and Prakash L (2005). Eukaryotic translesion synthesis DNA polymerases: specificity of structure and function. Annu. Rev. Biochem. 74: 317-353.

Qin S and Parthun MR (2006). Recruitment of the type B histone acetyltransferase Hat1p to chromatin is linked to DNA double-strand breaks. Mol. Cell Biol. 26: 3649-3658.

Raisner RM and Madhani HD (2006). Patterning chromatin: form and function for H2A.Z variant nucleosomes. Curr. Opin. Genet. Dev. 16: 119-124.

Tamburini BA and Tyler JK (2005). Localized histone acetylation and deacetylation triggered by the homologous recombination pathway of double-strand DNA repair. Mol. Cell Biol. 25: 4903-4913.

van Attikum H and Gasser SM (2005a). ATP-dependent chromatin remodeling and DNA double-strand break repair. Cell Cycle 4: 1011-1014.

van Attikum H and Gasser SM (2005b). The histone code at DNA breaks: a guide to repair? Nat. Rev. Mol Cell Biol. 6: 757-765.

Wyatt MD and Wilson DM III (2009). Participation of DNA repair in the response to 5-fluorouracil. Cell Mol. Life Sci. 66: 788-799.

Yu Y, Teng Y, Liu H, Reed SH, et al. (2005). UV irradiation stimulates histone acetylation and chromatin remodeling at a repressed yeast locus. Proc. Natl. Acad. Sci. U. S. A. 102: 8650-8655. 